\title{
Association between Artificial Reproductive Technology and Retinopathy of Prematurity
}

\author{
Kiril Slaveykov*, Kalina Trifonova, Hristo Mumdzhiev \\ Department of Internal Disease and General Medicine, Trakia University, Stara Zagora, Bulgaria
}

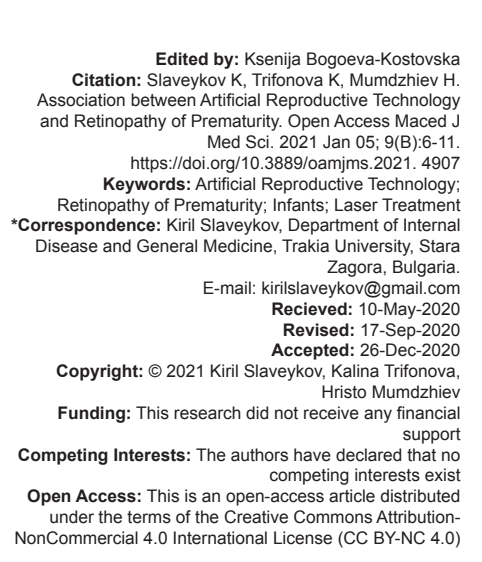

Introduction

Infertility has become an increasingly common health problem and has been estimated to affect approximately $10 \%$ of women in the reproductive age. There are three main therapeutic strategies pharmacological therapy, surgical therapy, and assisted reproductive technology (ART) [1]. Infertility is accepted as a social disease by the World Health Organization. ART becomes a common treatment, suggesting a greater focus on the consequences of this technology. ART has been linked to prematurity, low birth weight (BW), and higher incidence of multiple births among newborn. These children make up a considerable portion of the retinopathy of prematurity (ROP) screening burden and are likely to increase as ART is increasingly available and utilized [2]. The technological advances in neonatal care improve the survival rates even of preterm infants of very low gestational ages (GAs) and BWs, which leads to an increase in the incidence of ROP [3]. If the condition is not fixed and treated in a timely manner, it could lead to permanent and irreversible blindness.

ROP is a potentially blinding vasoproliferative disease in premature babies. It is generally associated with oxygen therapy applied to overcome the underdevelopment of their lungs. ROP is a leading cause of blindness in the low BW infants $(<1250 \mathrm{~g}$, mean $700 \mathrm{~g}$ ) in the developed world despite current treatment and is becoming increasingly prevalent in larger infants (<2000 g, mean $1400 \mathrm{~g}$ ) in the developing world. The world-wide prevalence of blindness due to ROP is 50,000 [4].

The number of ART cycles in Europe increases in each year, pregnancy rates also increase, while fewer embryos are transferred and multiple delivery rates decline [5]

There is a lack of consistency across studies for the association between ART and ROP. Some of them suggest a direct dependence [6], while others consider in vitro fertilization (IVF) either solely as a risk factor [7], or only slightly higher odds of ROP and a possible association [2]. Some even attribute the increased ROP incidence on other accompanying risk factors such as low BW, hyaline membrane disease [8], GA [9], seizure disorders, intraventricular hemorrhages [10], poor postnatal growth in the $1^{\text {st }}$ week of life [11], early postnatal hyperglycemia [12], and low APGAR score and oxygen therapy [13]. 
The aim of the study was to assess the association between ART and the development of ROP.

\section{Materials and Methods}

Institutional review board approval was obtained to perform a retrospective review of consecutive born infants at the Neonatal Intensive Care Unit in the University Hospital "Prof. Dr. Stoyan Kirkovich" in the city of Stara Zagora, Bulgaria, for a 4 years period (January 2016-December 2019). The screening criteria for inclusion in the study were GA $<32$ gestational weeks (GWs) and/or BW <1500 g. Initial ophthalmologic examinations were performed 4-6 weeks after birth. Outside of these criteria were included infants: With high oxygen demands, needing mechanical ventilation, with unstable courses, with complications, or at the discretion of a neonatologist. Infants were divided into two groups - conceived naturally or by ART. Those falling in the inclusion criteria were further divided according to their BW in four groups: BW <900 g, 900-1200 g, 1200$1500 \mathrm{~g}$, and >1500 g. Patients with pre-existing congenital disorders and those who died during initial hospitalization were excluded from the study. Information taken from the records included: Gender, BW, GA, type of conception, multiple births, and complications of prematurity. The zone and stage of ROP were documented in accordance with the International Classification for ROP. Examinations were performed by one of the two examiners (Kiril Slaveykov or Kalina Trifonova).

Statistical analyses were performed using Statistical Package for the Social Sciences (SPSS) 16. Binary logistic regression was performed separately on all risk factors to test their association with ROP requiring treatment.

$$
\begin{array}{r}
P=\exp (a+b 1 \times 1+b 2 \times 2+b 3 \times 3+\ldots) / \\
1+\exp (a+b 1 \times 1+b 2 \times 2+b 3 \times 3+\ldots)
\end{array}
$$
category,

$\mathrm{P}=$ the probability that a case is in a particular

exp=the exponential function (approx. 2.72),

$\mathrm{a}=$ the constant (or intercept) of the equation and, variables.

$b=$ the coefficient (or slope) of the predictor

A multi-factor model was then constructed using risk factors that were suggestive of association with a need for laser treatment, defined as $p<0.1$ in the previous analysis [14].

$$
y=b 1 \times 1+b 2 x 2+\ldots+b n x n+c .
$$

Here, b's $(i=1,2 \ldots n)$ are the regression coefficients, which represent the value at which the criterion variable changes when the predictor variable changes.

$$
\begin{aligned}
& \mathrm{y}=\text { dependent variable } \\
& \mathrm{x}=\text { independent variables } \\
& \mathrm{c}=\text { residual value }
\end{aligned}
$$

Risk factor that remained significant at $p<0.1$ was then used in a second multi-factor analysis. These data were subsequently used to define the statistically significant factor $p<0.05$. The infants requiring laser treatment were compared for mean BW and GA for both ART and natural birth. Student's t-test was used to determine if there was a significant difference in both cases. Tests for interactions between variables were also performed in SPSS 16 [15].

\section{Results}

A total of 5400 children were admitted, for the 4-year period, in the Clinic of Neonatology in the University Hospital "Prof. Dr. Stoyan Kirkovich" - Stara Zagora, Bulgaria. Out of them, 944 (17.48\%) were preterm (the neonatology clinic is a tertiary center of South-East Bulgaria), and out of them. 419 (44.39\%) fell in the inclusion criteria for ROP screening (Table 1).

Gender distribution was nearly equal, with $215(50.31 \%)$ being male and 204 (48.69\%) - female. During the research period, there were 15 cases of twins $(7.2 \%)$ and 3 cases of triplets $(2.1 \%)$. There were no cases of quadruplets or more. Mean maternal age was 27.4 years. The documented complications in the infants were grouped into four categories - respiratory complications $(54.2 \%)$, intraventricular hemorrhage $(8.8 \%)$, hemolytic disease $(1 \%)$, and sepsis and meningitis $(0.2 \%)$. Of the screened infants, 265 were conceived naturally and 154 through ART. Thirty-two $(7.6 \%)$ children required laser treatment for ROP, among them $15(5.7 \%)$ were conceived naturally and $17(11 \%)$ by ART (Table 2$)$.

Out of the 15 natural conception infants, requiring laser treatment, 14 (93.3\%) were singleton and $1(6.7 \%)$ was a twin. Among the 17 ART infants, $15(88.2 \%)$ were singleton and $2(11.8 \%)$ were twins. In single factor analysis, we found that gender, multiple pregnancy, sepsis, and meningitis are not statistically significant factors associated with severe ROP, requiring laser treatment. On the other hand, BW, GA, maternal age, mode of conception, respiratory complications, intraventricular hemorrhage, and hemolytic disease are relevant $(p<0.1)$ (Table 3$)$.

When the relevant factors from the single factor analysis were combined in the initial multifactor analysis maternal age, respiratory complications, intraventricular 
Table 1: Infants admitted in the neonatology clinic for the 2016-2019 period

\begin{tabular}{|c|c|c|c|c|c|c|}
\hline Birthplace & In term & & Preterm & & Total & \\
\hline Maternity ward & number & Out of them died (\%) & number & Out of them died $(\%)$ & number & Out of them died (\%) \\
\hline Maternity ward Stara Zagora & 4372 & $6(0.13)$ & 771 & $39(5.06)$ & 5143 & $45(0.87)$ \\
\hline Other maternity wards in the region & 84 & $7(8.33)$ & 173 & $28(16.18)$ & 257 & $35(13.62)$ \\
\hline Total & 4456 & $13(0.29)$ & 944 & $67(7.09)$ & 5400 & $80(1.48)$ \\
\hline
\end{tabular}

Table 2: Characteristics of included patients

\begin{tabular}{llll}
\hline Characteristic & Natural & ART & All \\
\hline All included patients & 265 & 154 & 419 \\
Mean BW in g standard deviation (SD) & $1254.45(236)$ & $1206.62(245)$ & $1236.71(240)$ \\
Mean GW (SD) & $296 / 7(16 / 7)$ & $293 / 7(15 / 7)$ & $295 / 7(16 / 7)$ \\
Gender & & & \\
$\quad$ Male & $133(50.18 \%)$ & $82(53.25 \%)$ & $215(51.31 \%)$ \\
$\quad$ Female & $132(49.82 \%)$ & $72(46.75 \%)$ & $204(48.69 \%)$ \\
Maternal age & & & \\
$\quad$ Mean maternal age (SD) & $25.8(6.8)$ & $31.3(7.5)$ & $27.4(7.6)$ \\
Multiple pregnancy & & & \\
$\quad$ Singleton & $253(95.47 \%)$ & $127(82.47 \%)$ & $380(90.7 \%)$ \\
$\quad$ Twins & $12(4.53 \%)$ & $18(11.69 \%)$ & $30(7.2 \%)$ \\
$\quad$ Triplets & 0 & $9(5.84 \%)$ & $9(2.1 \%)$ \\
Complications & $102(38.5 \%)$ & $48(31.2 \%)$ & $150(35.8)$ \\
$\quad$ None & $140(52.8 \%)$ & $87(56.5 \%)$ & $227(54.2 \%)$ \\
$\quad$ Respiratory complications & 0 & $1(0.6 \%)$ & $1(0.2 \%)$ \\
$\quad$ Sepsis and meningitis & $20(7.5 \%)$ & $17(11 \%)$ & $37(8.8 \%)$ \\
Intraventricular hemorrhage & $3(1.1 \%)$ & $1(0.6 \%)$ & $4(1 \%)$ \\
$\quad$ Hemolytic disease & $15(5.7 \%)$ & $17(11 \%)$ & $32(7.6 \%)$ \\
Treatment & $352 / 7$ & 36 & $355 / 7$ \\
$\quad$ Laser & & & \\
$\quad$ Mean GA at laser treatment & & & \\
\hline $\begin{array}{l}\text { SD: Standard deviation; ART: Artificial reproductive technology; GA: Gestational age; GW: Gestational } \\
\text { week; BW: Birth weight. }\end{array}$ &
\end{tabular}

hemorrhage, and hemolytic disease lost their significance $(p>0.1)$. A second multifactor analysis was performed on the remaining three factors, after controlling the effect for the removed factors, and the method of conception also lost its significance $(p>0.05)$. Finally, the only two statistically significant risk factors were BW and gestation age $(p<$ 0.05) (Table 4). Upon further analysis ART conception showed a statistically significant correlation with both BW and $\mathrm{GA}(\mathrm{p}=0.049$, Pearson correlation $=-0.096$ and $p=$ 0.09 , Pearson correlation $=0.912$, respectively) .

Table 3: Single factor logistic regression analysis

\begin{tabular}{llll}
\hline Risk factor & $\mathrm{p}$-value & odds ratio (OR) & $95 \%$ confidence interval $(\mathrm{Cl})$ \\
\hline Gender & 0.344 & 1.424 & $0.684-2.965$ \\
Weight & $<0.001$ & 0.984 & $0.979-0.989$ \\
$\mathrm{GA}$ & $<0.001$ & 0.092 & $0.042-0.200$ \\
Maternal age & 0.027 & 1.053 & $1.006-1.103$ \\
Multiple births & 0.748 & 0.842 & $0.295-2.400$ \\
Conception & 0.049 & 2.068 & $1.002-4.270$ \\
Respiratory complications & 0.006 & 5.525 & $1.628-18.744$ \\
Sepsis and meningitis & 1.00 & 000 & 000 \\
Intraventricular hemorrhage & 0.007 & 7.656 & $1.740-33.685$ \\
Hemolytic disease & 0.031 & 16.333 & $1.294-206.163$ \\
\hline GA: Gestational age; OR: Odds ratio; Cl: Confidence interval.
\end{tabular}

The method of conception showed statistically significant main effect $(p=0.049)$ as a single factor and high OR (2.639) interaction effect in multi-factor analysis, with an increased probability $(72.5 \%)$ of ROP requiring laser treatment. When we used multinomial multi-factor analysis for association with ROP stage, ART conception showed a statistically significant association ( $p=0.023$ ) and high OR (3.212) with stage
3 ROP, making it more likely ( $76.25 \%$ probability) to cause advanced ROP, even when treatment was not required (Table 5 ).

The mean BW for the 419 screened infants was $1236.71 \pm 240 \mathrm{~g}$ and the mean gestation age was 29 $5 / 7 \pm 16 / 7$ weeks. There was a statistically significant difference between the groups on both indicators (1254.45 $\pm 236 \mathrm{~g}$ and $296 / 7 \pm 16 / 7$ g.w. for natural conception compared to $1206.62 \pm 245 \mathrm{~g}$ and $293 / 7 \pm 1$ $5 / 7$ g.w. for ART, $p<0.05)$. ART infants also underwent laser treatment at a higher $\mathrm{GA}(\mathrm{p}<0.05)$ (Table 6).

\section{Discussion}

There is no centralized database or portal in Bulgaria where the information for maternity wards in other cities is held. The existing discharge summaries do not contain any information about the type of conception. Follow-up after laser treatment is difficult, due to being available in only few large cities. This makes estimates about the number of screened preterm infants in other regions and the country as a whole impossible. A study from 2016 reports 67585 children born in Bulgaria in 2014, with 6349 (9.39\%) from them preterm. The same study also notes there is no official data on incidence and prevalence of ROP among those infants [16]. Marinov in his PhD thesis performed ROP screening between September 2009 and February 2012, in the region of Plovdiv. He examined 132 preterm infants, following the same criteria as ours, and report 30.3\% developing ROP and $12.1 \%$ requiring laser treatment [17]. Mladenov et al. screened 1490 infants in the capital of Bulgaria - Sofia for the period June 2010-January 2016, showing similar results to ours, with $22.8 \%$ of infants developing ROP and $7.6 \%$ requiring treatment [18].

The main aim of the study was to assess the connection between ART and development of ROP. Using single factor analysis, ART was associated with two-fold increase in development of ROP, requiring

Table 4: Multiple factor logistic regression analysis

\begin{tabular}{|c|c|c|c|c|c|c|}
\hline Analysis & Analysis & & & Analysis & & \\
\hline Risk factor & $p$-value & Adj OR & $95 \% \mathrm{Cl}$ & p-value & Adj OR & $95 \% \mathrm{Cl}$ \\
\hline Weight & 0.005 & 0.989 & $0.981-0.997$ & 0.008 & 0.990 & $0.983-0.997$ \\
\hline GA & 0.049 & 0.325 & $0.106-0.998$ & 0.029 & 0.296 & $0.099-0.882$ \\
\hline Conception & 0.079 & 2.834 & $0.886-9.066$ & 0.069 & 2.639 & $0.928-7.506$ \\
\hline Maternal age & 0.845 & 0.993 & $0.926-1.065$ & - & - & - \\
\hline Respiratory complications & 0.417 & 0.455 & $0.068-3.043$ & - & - & - \\
\hline Intraventricular hemorrhage & 0.960 & 0.942 & $0.090-9.838$ & - & - & - \\
\hline Hemolytic disease & 0.434 & 8.188 & $0.042-1595.974$ & - & - & - \\
\hline
\end{tabular}


Table 5: Regression analysis for ART and ROP stage

\begin{tabular}{llll}
\hline ROP stage & $\mathrm{p}$-value & OR & $95 \% \mathrm{Cl}$ \\
\hline Stage 2 & 0.591 & 1.229 & $0.579-2.610$ \\
Stage 3 & 0.023 & 3.212 & $1.176-8.772$ \\
\hline ART: Assisted reproductive technology; ROP: Retinopathy of prematurity; OR: Odds ratio; Cl: Confidence \\
interval.
\end{tabular}

laser treatment. In multi-factor analysis, the interaction effect of ART lost its statistical significance, though $\mathrm{p}<0.1$, while the OR remained high (2.639). In a separate multi-factor analysis, independent of laser treatment, ART was proven to have a statistically significant association with advanced stages of ROP (Stage 3, p = 0.023). The independent and significant factors connected with ROP requiring treatment were low BW and gestation age.

Table 6: Student's t-test between ART and natural conception

\begin{tabular}{llll}
\hline Category & Natural & ART & p-value \\
\hline Mean BW in grams (SD) & $1254.45(236)$ & $1206.62(245)$ & 0.049 \\
Mean GA in weeks (SD) & $296 / 7(16 / 7)$ & $293 / 7(15 / 7)$ & 0.009 \\
BW in children requiring laser (SD) & $828(81)$ & $880(119)$ & 0.161 \\
GA in lasered children (SD) & $266 / 7(6 / 7)$ & $271 / 7(6 / 7)$ & 0.43 \\
Mean age for laser in children (SD) & $35.33(0.9)$ & $36(1.1)$ & 0.075 \\
\hline ART: Assisted reproductive technology; SD: Standard deviation; GA: Gestational age; BW: Birth weight.
\end{tabular}

Other studies on the subject report conflicting results, ranging from a direct connection, to just a tendency, or to no association at all. Chan et al. are one of the first teams to show a statistically significant association between ART population and severe ROP requiring treatment in nonblack infants $(\mathrm{OR} 4.70, \mathrm{Cl}$ $1.52-14.57 ; p=0.007)$. The study found a five-fold increase in ROP risk for ART infants regardless of BW [6]. Mladenov et al. report method of conception as a significant factor for both developing ROP $(p<0.001)$ and ROP progression, requiring treatment $(p=0.006)$ [18]. Watts and Adams also found an association between assisted reproduction and threshold ROP, though their study suggests IVF, rather than other ART techniques, as the major risk factor [7]. Yau et al. confirm the significance of IVF as an independent risk factor for Type $1 \mathrm{ROP}(\mathrm{OR}=6.17$; $\mathrm{Cl}$ : $1.15-45.83 ; p=0.04)$, as well as leading to a higher risk for multiple pregnancies [19]. McKibbin et al. also related a higher incidence of threshold ROP among multiples born from assisted pregnancies [20], as well as ART babies being a large proportion of those reaching stage 3 diseases and of those requiring treatment [21]. These results are summarized in a meta-analysis by Gao et al., who found significant association between the use of ART and ROP occurrence in the offspring $(\mathrm{OR}=1.34,95 \% \mathrm{Cl}: 1.05$ to $1.73, \mathrm{p}=0.02)$, but notes that this is due to the influence from a subgroup of ART, the IVF [22].

Our team's previous work, a meta-analysis from 2018, supports the current results. The research concluded that most studies show at least a tendency and ART newborns need to be considered as a risk group for ROP and observed with greater suspicion [23]. This is confirmed by Yonekawa et al., who suggest that there may be association between assisted conception (AC) and ROP. The study also supports our finding that
ART infants require laser treatment at a later $G A$ than those conceived naturally [24]. Similarly, to our findings Wong et al. found that there is no difference in the early stages of ROP for both assisted and natural conceived infants, however, once they develop stage 3 diseases, they may be at higher risk for treatment-requiring ROP [25]. Barker et al. find no significant difference between the numbers of babies developing ROP in the ART versus non-ART groups. However, they also note the small number of participants in the study and the slightly higher estimated odds of developing ROP in the ART babies, so a possible association is not entirely ruled out [2].

Ho et al. compare twin pregnancies and find no increase in risk for pregnancy complications and adverse perinatal outcome (including ROP) for the ART-conceived pregnancies [26]. Marinov in his PhD thesis does not find ART statistically significant factor for developing ROP or progression requiring treatment [17]. Friling et al. also did not find assisted reproduction to be a risk factor for developing ROP, with GA and BW remaining the significant factors [27]. This is also confirmed by Chiarelli et al. who conclude that among singleton infants born very preterm, mode of conception is not associated with overall mortality/morbidity or length of stay [28]. Funnel and Dabbs even note a reversal of the trend toward increasing ROP screening as a result of $A C$, due to the reduced percentage of $A C$ babies born at $<1500 \mathrm{~g}$ and less 32 weeks gestation [29].

Caucasian race has been found to be an independent risk factor for developing severe ROP [30]. Our study includes mainly White/European with only three African American infants, which limits the ethnicity/race comparison.

We tried to limit the effect of postnatal complications on development of severe ROP by performing multi-factor logistic regression analysis. Due to the retrospective nature of the study, there was no information concerning maternal complications during pregnancy, which might have further influenced ROP development.

There were no stage 5 ROP cases and only one case of stage 4, which progressed to partial detachment despite laser treatment, which limits associations between method of conception and the most severe form of ROP.

\section{Conclusion}

ART is a risk factor for ROP only when considered as a single independent factor. When a multi-factor interaction effect is introduced, it loses its significance and influences the severity of ROP through its correlation with very low BW and gestation 
age, rather than a directly increasing the possibility for it. Despite this, there is a pronounced trend for more severe ROP, even when treatment is not required, in ART children compared to naturally conceive in the same weight group.

\section{References}

1. Szamatowicz M. Assisted reproductive technology in reproductive medicine-possibilities and limitations. Ginekol Pol. 2016;87(12):820-3. https://doi.org/10.5603/gp.2016.0095 PMid:28098933

2. Barker L, Bunce C, Husain S, Adams GG. Is artificial reproductive technology a risk factor for retinopathy of prematurity independent of the generation of multiple births? Eur J Ophthalmol. 2017;27(2):174-8. https://doi.org/10.5301/ ejo.5000832

3. Valentine PH, Jackson JC, Kalina RE, Woodrum DE. Increased survival of low birth weight infants: Impact on the incidence of retinopathy of prematurity. Pediatrics. 1989;84(3):442-5. PMid:2788864

4. Gilbert C. Retinopathy of prematurity: A global perspective of the epidemics, population of babies at risk and implications for control. Early Hum Dev. 2008;84(2):77-82. https://doi org/10.1016/j.earlhumdev.2007.11.009 PMid: 18234457

5. De Geyter C, Calhaz-Jorge C, Kupka MS, Wyns C, Mocanu E, Motrenko T, et al. ART in Europe, 2014: Results generated from European registries by ESHRE: The European IVFmonitoring consortium (EIM) for the European society of human reproduction and embryology (ESHRE). Hum Reprod. 2018;33(9):1586-601. https://doi.org/10.1093/hropen/hoaa038 PMid:30032255

6. Chan RP, Yonekawa Y, Morrison MA, Sun G, Wong RK, Perlman $\mathrm{JM}$, et al. Association between assisted reproductive technology and advanced retinopathy of prematurity. Clin Ophthalmol. 2010;4:1385-90. https://doi.org/10.2147/opth.s15587 PMid:21179223

7. Watts $\mathrm{P}, \mathrm{Adams} \mathrm{GG}$. In vitro fertilisation and stage 3 retinopathy of prematurity. Eye (Lond). 2000;14(3):330-3. https://doi. org/10.1038/eye.2000.82

PMid:11026994

8. Gupta VP, Dhaliwal U, Sharma R, Gupta P, Rohatgi J. Retinopathy of prematurity-risk factors. Indian J Pediatr. 2004;71(10):887-92. https://doi.org/10.1007/bf02830827 PMid: 15531829

9. Darlow BA, Horwood LJ, Clemett RS. Retinopathy of prematurity: Risk factors in a prospective population-based study. Paediatr Perinat Epidemiol. 1992;6(1):62-80. https://doi. org/10.1111/j.1365-3016.1992.tb00747.x PMid:1553319

10. Brown DR, Milley JR, Ripepi UJ, Biglan AW. Retinopathy of prematurity: Risk factors in a five-year cohort of critically ill premature neonates. Am J Dis Child. 1987;141(2):154-60. https://doi.org/10.1001/archpedi.1987.04460020044024 PMid:3101483

11. Holmström G, Broberger $U$, Thomassen P. Neonatal risk factors for retinopathy of prematurity-a population-based study. Acta Ophthalmol Scand. 1998;76(2):204-7. https://doi. org/10.1034/j.1600-0420.1998.760216.x

\section{PMid:9591954}

12. Garg R, Agthe AG, Donohue PK, Lehmann CU. Hyperglycemia and retinopathy of prematurity in very low birth weight infants. J Perinatol. 2003;23(3):186-94. https://doi.org/10.1038/ sj.jp.7210879

PMid:12732854

13. Alajbegovic-Halimic J, Zvizdic D, Alimanovic-Halilovic E, Dodik I, Duvnjak S. Risk factors for retinopathy of prematurity in premature born children. Med Arch. 2015;69(6):409-13. https:// doi.org/10.5455/medarh.2015.69.409-413 PMid:26843736

14. DeAngelis MM, Ji F, Kim IK, Adams S, Capone A, Ott J, et al. Cigarette smoking, CFH, APOE, ELOVL4, and risk of neovascular age-related macular degeneration. Arch Ophthalmol. 2007;125(1):49-54. https://doi.org/10.1001/ archopht.125.1.49

PMid: 17210851

15. DeAngelis MM, Lane AM, Shah CP, Ott J, Dryja TP, Miller JW. Extremely discordant sib-pair study design to determine risk factorsfor neovascular age-related macular degeneration. Arch Ophthalmol. 2004;122(4):575-80. https://doi.org/10.1001/ archopht.122.4.575

PMid:15078676

16. Grozeva E, Simova J, Vankova D, Naneva Z, Grupcheva C. Retinopathy of prematurity-a bulgarian perspective of a global epidemic. Scr Sci Salutis Public. 2016;2(1):37-45. https://doi. org/10.14748/sssp.v1i1.1499

17. Marinov V. Retinopathy of the Prematurity-Incidence, Predictive Factors, Stages and Behavior. Dissertation Work, Bulgaria, Plovdiv; 2013.

18. Mladenov O, Chernodrinska V, Petkova I, Dimitrova G, Kemilev $\mathrm{P}$, Oscar $\mathrm{AH}$, et al. Retinopathy of prematurityincidence and risk factors in Bulgaria. Int J Pharm Sci Invent. 2017;6(7):18-23. https://doi.org/10.7546/crabs.2020.02.18

19. Yau GS, Lee JW, Tam VT, Yip S, Cheng E, Liu CC, et al Incidence and risk factors for retinopathy of prematurity in multiple gestations: A Chinese population study. Medicine (Baltimore). 2015;94(18):e867. https://doi.org/10.1097/ md.0000000000000867 PMid:25950699

20. McKibbin M, Booth AP, Dabbs TR. In vitro fertilisation and stage 3 retinopathy of prematurity. Eye (Lond). 2001;15(3):363-4. PMid: 11450754

21. McKibbin M, Dabbs TR. Assisted conception and retinopathy of prematurity. Eye (Lond). 1996;10(4):476-8. https://doi. org/10.1038/eye.1996.105 PMid:8944102

22. Gao L, Shao W, Li N, Tian C, Jia H, Peng X, et al. The risk of retinopathy of prematurity in the Infants following assisted reproductive technology: A meta-analysis. Biomed Res Int. 2019;2019:2095730. https://doi.org/10.1155/2019/2095730 PMid:31380413

23. Trifonova K, Slaveykov K, Mumdzhiev H, Dzhelebov D. Artificial reproductive technology-a risk factor for retinopathy of prematurity. Open Access Maced J Med Sci. 2018;6(11):2245-9. PMid:30559896

24. Yonekawa $Y$, Sun $G$, Weissman $M$, Perlman JM, Shin $H$, Chiang MF, et al. The association between assisted conception and progression of retinopathy of prematurity. Invest Ophthalmol Vis Sci. 2008;49(13):1400.

25. Wong RK, Yonekawa Y, Sun G, DeAngelis MM, Morrison M, Chiang MF, et al. Update: Assisted conception and progression of retinopathy of prematurity. Invest Ophthalmol Vis Sci. 2009;50(13):3143.

26. Ho CH, Peng FS, Chen HF, Lien YR, Chen SU, Yang YS. 
Twin pregnancies conceived by assisted reproductive technology: Maternal and perinatal outcomes. Taiwan J Obstet Gynecol. 2005;44(4):332-7. https://doi.org/10.1016/ s1028-4559(09)60166-2

27. Friling $R$, Axer-Siegel R, Hersocovici Z, Weinberger D, Sirota L, Snir M. Retinopathy of prematurity in assisted versus natural conception and singleton versus multiple births. Ophthalmology. 2007;114(2):321-4. https://doi.org/10.1016/j.ophtha.2006.11.010 PMid:17270680

28. Chiarelli L, Mirea L, Yang J, Lee SK, Shah PS, on Behalf of the Canadian Neonatal Network. Neonatal outcomes in very preterm singleton infants conceived using assisted reproductive technologies. Am J Perinatol. 2015;32(6):515-22. https://doi. org/10.1055/s-0034-1396699

PMid:25539408

29. Funnell CL, Dabbs TR. Assisted conception and retinopathy of prematurity: 8-year follow-up study. Eye (Lond). 2007;21(3):383-6. https://doi.org/10.1038/sj.eye.6702215 PMid: 16410811

30. Yang MB, Donovan EF, Wagge JR. Race, gender, and clinical risk index for babies (CRIB) score as predictors of severe retinopathy of prematurity. J AAPOS. 2006;10(3):253-61. https:// doi.org/10.1016/j.jaapos.2006.01.004

PMid: 16814180 